\title{
UK drug agency announces review of use of alteplase after stroke
}

\author{
() $(1) \Theta$ OPEN ACCESS
}

\author{
Deborah Cohen, Helen Macdonald
}

The BMJ

The UK Medicines and Healthcare Products Regulatory Agency has announced it is to review the "balance of benefits and risks" of the use of alteplase in the treatment of acute ischaemic stroke.

In a letter published in the Lancet on 23 August, ${ }^{1}$ Ian Hudson, chief executive of the MHRA, announced that the agency was setting up a panel of experts to review "any new information or concerns about the data that underpin the present marketing authorisation" for the drug, but he added that the data supporting alteplase use had been "extensively discussed" and that the "benefit-risk balance is favourable.,

The MHRA's announcement was prompted by concerns raised by Roger Shinton, a former consultant physician at

Birmingham's Heartlands Hospital in another letter in the same issue of the Lancet. $^{2}$

Alteplase, a thrombolytic drug, is licensed in Europe for the management of acute ischaemic stroke within four and a half hours of onset of symptoms and in the United States for use within three hours. In his letter Shinton highlighted several concerns with the initial trial used to obtain marketing approval for alteplase $\mathrm{e}^{3}$ and a subsequent trial that was key to extending its window of use in Europe from three to four and a half hours. ${ }^{4}$ In the first trial, called the National Institute of Neurological Disorders and Stroke (NINDS) trial, participants were randomised to either alteplase or placebo within three hours of the onset of symptoms after a haemorrhagic stroke had been ruled out. Concerns had previously been raised that the placebo and treatment groups in this trial were not evenly matched because the placebo group had more patients with more severe stroke than the treatment arm, and Shinton's letter raised other concerns. $^{2}$

Shinton said that his own analysis of the trial indicated that the favourable outcomes shown for alteplase were driven by a couple of trial centres. He added that the NINDS trial had shown a mortality benefit within 30 days and that this has not been replicated in any other major trial. In four trials sponsored by the industry the 30 day mortality figure was similar in two studies and $5 \%$ worse in two, he wrote.

One of the four was the trial that was used to support the application for the extended period of use in Europe, and this was the only trial to show a "positive" outcome. This outcome related to stroke symptoms (modified Rankin scale 0-1) rather than disability or loss of independence (modified Rankin scale
0-2). ${ }^{4}$ This trial, Shinton said, also had significantly fewer patients with a past history of stroke in the alteplase arm than in the placebo arm.

In 2012 the results of the third International Stroke Trial (IST-3), which had been set up to investigate the benefits and harms of alteplase in a wider range of patients, including older patients and those treated up to six hours after onset of symptoms, were published in the Lancet. ${ }^{5}$ These results indicated that patients taking alteplase were significantly more likely than patients taking placebo to be alive and independent if treated with alteplase within three hours (30.6\% versus $22.7 \%$ of patients (odds ratio 1.65 (99\% confidence interval 1.03 to 2.62))). However, no benefit was shown in patients treated between three and 4.5 hours $(31.5 \%$ versus $37.7 \%$ (odds ratio $0.73(0.50$ to 1.07$))$ ) or in those treated between 4.5 and six hours $(47.3 \%$ versus $42.6 \%$ (odds ratio 1.31 (0.89 to 1.93 ))).

In his letter to the Lancet Shinton pointed out that no statistically significant trend was shown in the trial between the outcomes and time to treatment, which casts doubt on the "time is brain" principle.

The initial phase of the trial was double blinded and placebo controlled, but then Boehringer Ingelheim, which holds the licence for the drug in Europe, stopped supplying the drug and placebo and the trial became open label. Shinton infers that there was a trend towards an adverse outcome associated with alteplase in the blinded stage.

Concerned about the greater bias of open label trials, coupled with an outcome of self rated symptoms and disability scores, Shinton managed to obtain unpublished data from the trial that had been submitted to the Lancet on the harder data assessed, such as eventual place of residence (own home, nursing home, hospital, and so on), which he has given to The BMJ. The data show no benefit for alteplase (table $\Downarrow$ ).

In another study a subgroup of IST-3 patients were followed up 18 months later and were asked to recall which treatment group they were in. ${ }^{6}$ Those who correctly recalled that they took alteplase were more likely than those who correctly recalled that they took placebo to report good outcomes $(66.7 \%$ versus $55.1 \%)$. Such a difference was not seen in groups of participants who could not recall their treatment group ( $48.6 \%$ versus $49.9 \%)$. 
Disability after stroke is associated with increased risk of death, but this follow-up study of IST-3 participants showed no reduction in mortality in those treated with alteplase after 18 months.

The IST-3 investigators have disputed Shinton's assessment of the NINDS trial, ${ }^{7}$ arguing that independent reviews of the data have indicated that there was a "statistically significant, and clinically important, benefit of t-PA [alteplase]." They added that Shinton's observation that a couple of centres were driving the outcomes "does not provide evidence of bias," as the "numbers are too small" to have an effect.

They said that Boehringer Ingelheim did not provide alteplase and placebo after the initial phase of the IST-3 trial "because their priority was to invest all available resources" in the completion of the trial used to get a licence extension for use of the drug up to four and half hours after symptom onset and to focus on setting up a registry.

In another response to Shinton's letter in the Lancet, the authors of a Cochrane review on thrombolysis for acute ischaemic stroke, ${ }^{8}$ some of whom were IST- 3 investigators, said that their recent meta-analysis showed evidence of benefit. ${ }^{9}$ This meta-analysis reported that with alteplase administered up to six hours after ischaemic stroke significantly more participants were alive or independent (modified Rankin scale 0-2) at three to six months after a stroke (odds ratio 1.17 (95\% confidence interval 1.06 to 1.29)) and that there was a larger benefit in giving the drug within three hours (odds ratio 1.53 (1.26 to 1.86)).

1 Hudson I. Alteplase for ischaemic stroke: responses. Lancet 2014:384:662-3.

2 Shinton R. Questions about authorisation of alteplase for ischaemic stroke. Lancet 2014:384:659-60.

3 National Institute of Neurological Disorders and Stroke rt-PA Stroke Study Group. Tissue plasminogen activator for acute ischemic stroke. New Engl J Med 1995:14:1581-7.

4 Hacke W. Thrombolysis with alteplase 3 to 4.5 hours after acute ischemic stroke. New Engl J Med 2008;359:1317-29.

5 IST-3 collaborative group. The benefits and harms of intravenous thrombolysis with recombinant tissue plasminogen activator within $6 \mathrm{~h}$ of acute ischaemic stroke (the third international stroke trial [IST-3]): a randomised controlled trial. Lancet 2012;379:2352-63.

6 IST-3 collaborative group. Effect of thrombolysis with alteplase within $6 \mathrm{~h}$ of acute ischaemic stroke on long-term outcomes (the third International Stroke Trial [IST-3]): 18-month follow-up of a randomised controlled trial. Lancet Neurol 2013;12:768-76.

7 Sandercock P, Lindley R, Wardlaw JM, Murray G, Whiteley W, Cohen G. Alteplase for ischaemic stroke: responses. Lancet 2014;384:660-1.

8 Wardlaw JM, Murray V, Berge E, del Zoppo GJ. Thrombolysis for acute ischaemic stroke. Cochrane Database Syst Rev 2014:7:CD000213.

9 Wardlaw JM, Murray V, Berge E, Del Zoppo GJ. Alteplase for ischaemic stroke: responses. Lancet 2014;384:661-2.

\section{Cite this as: BMJ 2014;349:95355}

This is an Open Access article distributed in accordance with the Creative Commons Attribution Non Commercial (CC BY-NC 3.0) license, which permits others to distribute, remix, adapt, build upon this work non-commercially, and license their derivative works on different terms, provided the original work is properly cited and the use is non-commercial. See: http://creativecommons.org/licenses/by-nc/3.0/. 


\section{Table}

Table 1| Place of residence at six months' completion of IST-3 trial (\%)*

\begin{tabular}{lll} 
Place & Treatment & Control \\
Own home & $805(53.1)$ & $799(52.6)$ \\
\hline Relative's home & $74(4.9)$ & $79(5.2)$ \\
\hline Residential home & $64(4.2)$ & $53(3.5)$ \\
\hline Nursing home & $115(7.6)$ & $119(7.8)$ \\
\hline Still in hospital & $6(0.4)$ & $9(0.6)$ \\
\hline Had died & $408(26.9)$ & $407(26.8)$ \\
\hline Question not answered & $1(0.1)$ & 0 \\
\hline Form not returned & $42(2.8)$ & $54(3.6)$ \\
\hline All & 1515 & 1520 \\
\hline
\end{tabular}

*These data were originally supplied to the Lancet by the IST-3 team but were not published. 